\title{
SEGURANÇA PÚBLICA BRASILEIRA: DIREITO FUNDAMENTAL SOCIAL PARTICIPATIVO
}

\author{
Guilherme Degraf ${ }^{1}$ \\ Valter Foleto Santin ${ }^{2}$ \\ Ilton Garcia da Costa ${ }^{3}$
}

\section{Resumo:}

O artigo visa demonstrar que a segurança pública consiste em direito fundamental social no contexto da Constituição Federal de 1988; e que além de dever do Estado é um direito e responsabilidade de toda a sociedade brasileira visando à paz social, com a preservação da ordem pública, da incolumidade das pessoas e do patrimônio. A pesquisa utilizou o método de abordagem indutivo-dedutivo, a técnica de documentação indireta e a pesquisa bibliográfica. Concluiu-se pela fundamental participação de toda sociedade brasileira na construção de um serviço público de segurança pública adequado, visando às métricas da qualidade e da excelência.

Palavras-chave: Constituição Federal de 1988, Direitos fundamentais, Direitos sociais, Segurança pública, Serviços públicos.

\section{BRAZILIAN PUBLIC SECURITY: PARTICIPATIVE SOCIAL FUNDAMENTAL LAW}

\begin{abstract}
:
The article aims to demonstrate that public security is a fundamental social right in the Federal Constitution of 1988; and that goes beyond of State obligation, it's a right and responsibility of all Brazilian society aiming at social peace, with the preservation of public order, the safety of people and property. The research used the method of inductive-deductive approach, the technique of indirect documentation and bibliographic research. It concluded for the fundamental participation of all Brazilian society in the construction of an adequate public security public service, aiming at the metrics of quality and excellence.
\end{abstract}

Keywords: Federal Constitution of 1988; Fundamental rights; Social rights; Public security; Public services.

\section{INTRODUÇÃO}

\footnotetext{
${ }^{1}$ Mestrando em Ciência Jurídica pela UENP (Jacarezinho-PR, Brasil). Especialista em Modernas Tendências da Criminologia, do Direito Penal e do Direito Processual Penal pela SECAL. Participante do GP Políticas públicas e direitos sociais. PRF. E-mail: gdegraf@gmail.com

${ }^{2}$ Professor do Mestrado e Doutorado da UENP (Jacarezinho-PR, Brasil). Doutor em Direito USP-SP. PósDoutor (Coimbra, Portugal). Líder do GP Políticas públicas e direitos sociais. Procurador de Justiça (SP). Email: santin@uenp.edu.br

${ }^{3}$ Professor do Mestrado e Doutorado da UENP (Jacarezinho-PR, Brasil). Doutor em Direito (PUC-SP). Líder do GP CERTOS. Advogado. E-mail: iltongcosta@gmail.com
} 
O presente artigo científico tem como objetivo analisar a segurança pública brasileira enquanto direito fundamental social; e a necessidade de construir a segurança pública com participação de toda a sociedade brasileira, em conformidade com o texto constitucional em vigor.

Para que tais objetivos sejam alcançados serão apresentados alguns levantamentos existentes na doutrina sobre tal temática; com o objetivo de aproximar o leitor do tema, o qual se revela importante para toda a coletividade.

A segurança pública adquiriu importância na percepção da sociedade brasileira, principalmente nas últimas décadas, onde a sensação de insegurança aumentou, principalmente nas grandes cidades, sendo pertinente analisar o tema.

Inicialmente, é preciso reconhecer que no Brasil, uma das temáticas que mais se discute de forma empírica é a questão da segurança pública, pois independentemente da classe social e das condições individuais, tal questão atinge de certa forma todos os cidadãos brasileiros, uns de forma mais traumática do que outros, mas nenhum indivíduo está livre das consequências da segurança pública posta.

A proposta deste artigo é apontar algumas percepções a respeito da segurança pública, a importância da segurança nos normativos internacionais e o consequente avanço no reconhecimento da segurança pública como direito fundamental social na Constituição Federal de 1988, e a participação de toda a sociedade brasileira neste contexto de construção da segurança pública numa perspectiva realmente coletiva e cidadã, por se tratar de direito e responsabilidade de todos.

Apontar também a segurança pública como serviço público essencial e fundamental aos direitos individuais e sociais, com necessidade de políticas públicas permanentes para a adequação prestacional de tal serviço público no Estado Brasileiro, visando o permanente processo de melhorias.

Para que os objetivos deste artigo científico sejam alcançados o mesmo se revestirá de caráter explicativo, multimodal, desenvolvido por meio do processo lógico-dedutivo.

A pesquisa utilizou o método de abordagem indutivo-dedutivo, os métodos de procedimento comparativo, a técnica de documentação indireta e, principalmente, a pesquisa bibliográfica, em livros, revistas científicas, em material disponível no ambiente virtual, e documental, e ainda a legislação existente. 


\section{SEGURANÇA PÚBLICA E SUA IMPORTÂNCIA NACIONAL E INTERNACIONAL PARA A BUSCA DA PAZ}

Evidentemente a segurança pública não é um problema isolado de determinada nação, mas sim um campo de atuação estatal presente em cada Estado existente, pois a paz social se revela tão importante externamente como internamente.

O tema da paz, a paz perpétua preconizada há muito por Kant, possuía uma ligação com a convivência entre os povos, evitando a guerra. Isso se relacionava ao conceito de que a razão tem mais força que o poder (KANT, 2008, p. 17-18), com a observação de que:

\footnotetext{
a razão, do trono do máximo poder legislativo moral, condena a guerra como via jurídica e faz, em contrapartida, do estado de paz um dever imediato, o qual não pode todavia estabelecer-se ou garantir-se sem um pacto entre os povos: - tem, pois, de existir uma federação de tipo especial, a que se pode dar o nome de federação da paz (foedus pacificum), que se distinguiria do pacto de paz (pactum pacis), uma vez que este tentaria acabar com uma guerra, ao passo que aquele procuraria pôr fim a todas as guerras e para sempre.
}

O estado de beligerância referia-se à disputa entre nações diversas, ligados à soberania e autodeterminação dos povos. A condenação da guerra entre os povos e o estabelecimento da paz entre as nações têm relação com a segurança pública atual, na busca da paz social, de convivência harmônica e pacífica entre os próprios cidadãos, de um mesmo povo e nação.

Kant pregava uma sociedade mais racional e humana, participando do iluminismo. Ele se opunha ao poder absolutista dos governantes, assim surge com concepções de defesa da obtenção da paz pelo direito, associando o povo a um federalismo pacífico; em contrapartida um comportamento mais submisso do Estado às normas internacionais, propondo um direito cosmopolita, ou seja, mais globalizado, de acordo com a ideia de que todo indivíduo é cidadão do mundo e dotado de dignidade.

As percepções idealistas de Kant canalizam visões inerentes aos valores éticojurídicos e à racionalização humana; ou seja, a capacidade de pensar, na tentativa de compor um conjugado de princípios universais totalmente capazes de nortear as relações humanas, sociais e estatais por meio da inteligência, da confiança e da boa-fé entre outros atores.

$\mathrm{Na}$ concepção filosófica kantiana, o atrelamento da vontade do povo para que exista paz ou guerra não se versa sobre considerações de justiça ou de moralidade, mas sim sobre a questão objetiva de saber qual é a importância para aqueles que padecem diretamente as 
torturas e os danos que a guerra produz. Kant em sua retórica invocação do direito à guerra corrobora a necessidade de que até mesmo os dominadores despóticos têm de legitimar suas políticas beligerantes.

Afastado destas ideias de sua época, mais ligados à guerra, e pensando no serviço público oferecido atualmente no Brasil, em matéria de segurança pública, se verifica sua legitimação pela busca da ordem e da paz social; e isto se materializa com o famoso contrato social, que estabelece o modelo mental de Estado que é adotado nas modernas democracias.

Ao que parece, no atual momento da humanidade, as convulsões sociais têm eclodido mais interna do que externamente; e isto dá mais relevância e importância à segurança pública de cada Estado do que suas respectivas forças armadas, que são voltadas ao público externo, no âmbito da defesa nacional como prioridade.

Evidentemente, a defesa da pátria através da adoção de forças armadas, apesar de serem dotadas de efetivos com armamentos com grande poder de fogo, não podem de forma alguma ser confundidos com os operadores da segurança pública, os quais também possuem dotação de armas de fogo, mas com finalidades bem diversas.

Os militares das forças armadas são capacitados para os conflitos externos e as funções de ferir ou matar os inimigos de seu país em situação de combate, em tempo de guerra declarada. Os policiais e os demais operadores da segurança pública diferentemente, não são legitimados para ferir, muito menos para matar as pessoas, salvo em legítima defesa ou outra excludente de ilicitude na análise do caso concreto. Pois não trabalham contra inimigos, mas diante de cidadãos que por algum motivo cometeram um crime ou uma contravenção penal.

Não é necessária uma declaração de guerra para atuação, pois a atividade policial é permanente, seja na atuação do policiamento preventivo ou do policiamento repressivo. Neste sentido Teixeira (2017, p. 15) estabelece a diferenciação:

Em virtude da finalidade da ação desenvolvida podemos ter a Polícia preventiva e a Polícia repressiva. A primeira tem por objeto a prevenção de perigos para a ordem e segurança pública, realizando, em geral, os serviços de inspeção e vigilância. A polícia repressiva, por sua vez, caracteriza-se por agir em situação em que o perigo já se concretizou em dano, sendo agora necessário limitar os efeitos danosos ou impedir a sua ampliação ou propagação. A polícia repressiva está a cargo das polícias criminais. É importante ressaltar que, a relação entre polícia preventiva e polícia repressiva é liminar. 
De modo geral, os operadores da segurança pública se destacam na capacidade de resolver conflitos, utilizando os meios necessários e com menor poder lesivo para a manutenção da ordem e da paz social que Kant buscava pela razão; mas lamentavelmente inúmeros conflitos e crimes ocorrem.

Em termos de prioridade parecem mais relevantes, diante da realidade brasileira, os investimentos em segurança pública do que nas forças armadas propriamente; pois os conflitos internos no Brasil são muito mais presentes do que as possibilidades de agressões com outras nações.

Nas últimas décadas, o Brasil utilizou muito mais suas forças armadas nas chamadas operações de garantia da lei e da ordem (GLO) do que em operações militares externas; o que demonstra possibilidades de atuação complementar das forças armadas na segurança pública interna, questão fática controversa revestida de realidade no Estado Brasileiro, o que demonstra a canalização de esforços para uma segurança pública mais efetiva.

Assim sendo, ao se buscar os tratados internacionais pode-se verificar que na Declaração Universal dos Direitos Humanos (DUDH) de 1948, em seu artigo III tem-se a previsão humanitária de que "todo ser humano tem direito à vida, à liberdade e à segurança pessoal". No mesmo sentido, o Pacto Internacional sobre direitos civis e políticos de 1966 dispõe sobre o direito de liberdade e segurança pessoais, em que toda pessoa tem direito à liberdade e à segurança pessoal $\left(\right.$ art. $\left.9^{\circ}, 1\right)$.

Ainda que a Constituição Federal de 1988 esteja eivada de normas programáticas, elencando expressamente inúmeros direitos fundamentais e direitos fundamentais sociais o fez com observação ao Preâmbulo da própria Magna Carta, de modo que o constituinte originário remete à busca de efetivação de um Estado de Bem-Estar Social. No atual estágio de desenvolvimento da nação brasileira este objetivo está distante de ser concretizado, entretanto parece ser o caminho idealizado e escolhido pelo constituinte de 1988.

Neste sentido, ao lecionar o deslocamento dos direitos sociais, na ideia de alcançar toda a sociedade brasileira, o que ainda não se efetivou na constatação prática diária, mas se apresenta como um balizamento do que se deve buscar, Carlos Miguel Herrera (2007, p. 390) escreve o seguinte:

A inscrição dos direitos sociais em uma modalidade específica de Estado Social, o Estado de Bem-Estar leva a um deslocamento de seus fundamentos, ou mais exatamente, à absolutização de uma de suas vertentes, com todas as consequências que dela derivam no plano jurídico. Sublinhamos que, neste modelo, os direitos 
sociais aparecem marcados duplamente pela marca do particularismo: um certo tipo de "direitos" (a prestações "sociais" concretas), próprio de uma certa categoria (os indigentes), para alcançar sua integração no conjunto social.

Assim sendo, fica mais do que evidente o dever do Estado em ser proativo, realmente atuante, na promoção das prestações positivas sociais mínimas e necessárias, objetivando melhoria da qualidade de vida de todos os cidadãos brasileiros, e isto se dá também nos serviços de segurança pública. Neste sentido Bonavides (2013, p. 343) escreve:

\footnotetext{
Não há para tanto outro caminho senão reconhecer o estado atual de dependência do indivíduo em relação às prestações do Estado e fazer com que este último cumpra a tarefa igualitária e distributiva, sem a qual não haverá democracia nem liberdade.
}

De modo que ao Estado cabe a tarefa de equilibrar as inúmeras desigualdades sociais, através do estabelecimento de políticas públicas de universalização de acesso aos usuários, daqueles serviços básicos que toda a população brasileira tem o direito. Nesta concepção também se reconhece o direito a uma segurança pública eficiente e adequada, as quais decorrem do próprio reconhecimento desta como direito fundamental social.

\section{DIREITOS FUNDAMENTAIS SOCIAIS NA CONSTITUIÇÃO}

O Brasil, ao ter sido constituído como Estado Democrático de Direito, optou pelo dever de garantir a inviolabilidade dos direitos fundamentais expressos na Constituição da República Federativa do Brasil de 1988 e muitos destes direitos são reconhecidos também no direito internacional.

Ao tratar da fundamentabilidade dos direitos sociais, primeiramente é necessário, mencionar sobre os direitos fundamentais de segunda geração, que são aqueles onde o Estado deve ter uma prestação positiva (do dever agir) no sentido de buscar a igualdade entre os desiguais, reduzindo as desigualdades da sociedade. Nesta concepção Lorenzetti (2011, p. 106) escreve o seguinte:

(...) as obrigações de fazer impõem obrigações ativas ao sujeito passivo. São características destas os denominados direitos econômico-sociais, como o direito ao trabalho e à moradia. (...) no caso das obrigações de fazer em benefício do sujeito ativo, trata-se de direitos de operatividade direta. Em virtude delas, o titular tem uma pretensão positiva, que sustenta uma ação processual. Existe uma ação positiva fática, já que, se for usada uma forma jurídica, tratar-se-á de uma obtenção da satisfação da pretensão. 
Da mesma forma, conceituando os direitos fundamentais de segunda geração, Bulos (2014, p. 403) ensina que:

(...) a segunda geração, advinda logo após a Primeira Grande Guerra, compreende os direitos sociais, econômicos e culturais, os quais visam assegurar o bem-estar e a igualdade, impondo ao Estado uma prestação positiva, no sentido de fazer algo de natureza social em favor do homem.

Costa, Veiga e Nogas (2019, p. 101) ao trabalhar a referida questão afirmam que: “Os direitos fundamentais passam a ser não só direitos dos indivíduos frente ao estado, mas passam a ser a base do ordenamento jurídico do Estado e da sociedade, vinculando o poder público, e os particulares nas relações com outros particulares.”

Ainda neste mesmo sentido de prestação positiva do Estado, Paulo e Alexandrino (2012, p. 98) lecionam:

(...) os direitos fundamentais de segunda dimensão - direitos sociais, culturais e econômicos - os direitos fundamentais passam a ter feição positiva, isto é, passaram a exigir, também, a atuação comissiva do Estado, prestações estatais em favor do bem-estar do indivíduo.

Assim sendo, observa-se que na atuação do Estado o agir é fundamental, quando se trabalha a ideia dos direitos fundamentais sociais. Em decorrência disso, a prestação do serviço de segurança pública deve neste diapasão ser reconhecido como um fazer estatal, uma efetiva prestação à sociedade como um todo. E ao fazer isso direcionado à coletividade, e não a um indivíduo específico estar-se-á diminuindo as desigualdades existentes. Da mesma forma, Costa, Veiga e Nogas (2019, p. 102) explicam:

Sendo também, nesse sentido, direitos de prestação, onde o indivíduo pode exigir do Estado, uma atuação positiva, e, portanto, prestacional, a partir de normas jurídicas que exigem uma atuação positiva do Estado para a proteção de bens jurídicos, e prestações materiais, que são normas que exigem do Estado uma atuação positiva para reduzir desigualdades sociais.

De modo que o Estado ao atuar de maneira positiva estará atuando na redução das desigualdades sociais, já que a prestação da segurança pública se reveste de um caráter endereçado a todos os cidadãos.

Por sua vez, Santin (2013, p. 25) amplia a percepção fazendo com que o direito social seja pensado como política pública efetiva, assim escreve que: 
As políticas públicas estabelecem a obrigatoriedade de prestações públicas positivas, traduzidas em serviços públicos, que podem ser exigidos pelo cidadão e pela sociedade, por sua configuração como direito individual, coletivo ou difuso, dependendo da modalidade da atividade estatal.

Assim sendo, os direitos sociais requerem uma atuação ativa do Estado na sua implantação na sociedade, de modo que as políticas públicas surgem como o veículo de realização dos direitos sociais constitucionalmente garantidos.

Na Constituição Federal de 1988 a segurança pública aparece em diversos momentos, algumas vezes cunhada apenas como segurança, mas com intuito de efetivação do direito à segurança pública. Tal concepção é destacada por Santin (2013, p. 47-48):

$\mathrm{Na}$ sua dimensão atual, o direito à segurança pública tem previsão expressa na Constituição Federal do Brasil (preâmbulo, arts. $5^{\circ}, 6^{\circ}$ e 144) e decorre do Estado Democrático de Direito (cidadania e dignidade da pessoa humana, art. $1^{\circ}$, II e III, $\mathrm{CF}$ ) e dos objetivos fundamentais da república (sociedade livre, justa e solidária e bem de todos, art. $3^{\circ}$, I e IV), com garantia do recebimento dos serviços respectivos. A segurança pública é considerada dever do Estado, direito e responsabilidade de todos, destinada à preservação da ordem pública e da incolumidade das pessoas e do patrimônio (art. 144, caput, CF), que implicam num meio de garantia da inviolabilidade do direito à vida, à liberdade, à igualdade, à segurança e à propriedade, direitos e garantias fundamentais do cidadão (art. $5^{\circ}$, caput, $\mathrm{CF}$ ). (...)

Importante destacar que em termos de segurança pública deve-se atentar para as atitudes estatais na prestação do serviço público respectivo e também a atuação do próprio indivíduo, pelo direito de participação (artigo 144 da Constituição Federal de 1988).

Outro aspecto a ser levantado é a discussão doutrinária no sentido de que a segurança pública seria um direito fundamental de quinta geração; de modo que os direitos sociais ocupariam a segunda geração em direitos humanos; porém Bonavides sustenta a ideia de que a segurança pública em conexão com o direito de paz como direito fundamental seria um direito de quinta geração.

De modo que há para este autor uma percepção diversa da maioria. Para ele não há como falar de segurança pública e direito social sem mencionar o direito fundamental da paz; sob este prisma, Bonavides (2013, p. 590) apresenta as seguintes considerações:

Estatutário de aspirações coletivas de muitos séculos, a paz é corolário de todas as justificações em que a razão humana, sob o pálio da lei e da justiça, fundamenta o ato de reger a sociedade, de modo a punir o terrorista, julgar o criminoso de guerra, encarcerar o torturador, manter invioláveis as bases do pacto social, estabelecer e conservar por intangíveis as regras, princípios e cláusulas da comunhão política. $\mathrm{O}$ 
direito à paz é o direito natural dos povos. Direito que esteve em estado de natureza no contratualismo de Rousseau ou que ficou implícito como um dogma na paz perpétua de Kant. Direito ora impetrado na qualidade de direito universal do ser humano.

Em termos diferentes, Valter Foleto Santin verifica a segurança pública como presente em todas as gerações de direito, não apenas numa, pela sua formatação de manutenção da paz social, sempre presente na sociedade em todos os momentos históricos, pela própria razão de ser do Estado moderno. Sobre isso Santin (2013, p. 47):

\footnotetext{
Em qualquer análise de geração ou onda de direitos não se pode prescindir da inclusão e atenção do direito à segurança pública, pela sua grande importância para a vida em sociedade, principalmente no momento atual em que a violência e a criminalidade explodem no mundo e no Brasil, especialmente em nossas cidades grandes e médias, em que até sair de casa para ir à esquina tomar um ar ou comprar leite e pão virou uma aventura de alto risco, mesmo nos bairros outrora tranquilos e seguros.

O direito à segurança pública enfeixa uma gama de direitos, pela sua característica de liberdade pública e até mesmo componente do direito da personalidade, por conter relações públicas e privadas, seja nas prestações estatais positivas e negativas como no respeito mútuo dos cidadãos à incolumidade e patrimônio alheios e na contribuição à preservação da ordem pública.
}

O direito à paz está intrínseco nos povos como um direito natural, direito este que esteve em "status naturalis" no contratualismo social de Rousseau e implícito na dogmática da paz perpétua, de Kant.

Em tese, o direito à paz é a mais inderrogável cláusula do contrato social, supremo direito da humanidade, pois a figura dos direitos humanos inserida na Constituição Federal atual é de certa maneira inspirada por filósofos iluministas, como Kant. Em decorrência disto se pode assegurar que a guerra é um crime e a paz é um direito.

Independentemente da classificação da segurança dentro das gerações de direitos, reveste-se tal direito como almejado por todos os povos; seja na relação entre Estados diversos externamente, seja na possibilidade de uma vida dentro de seu próprio Estado com as garantias mínimas de poder exercer seus demais direitos, sem que a insegurança os impeçam de ter uma vida com o mínimo de tranquilidade desejado.

Afinal buscar a paz social é o que se deseja para o desenvolvimento do indivíduo e do grupo social; por isto a segurança não é mero direito, mas sim direito fundamental social. 
Em um exame mais detalhado do texto constitucional, percebe-se que o constituinte estabeleceu a segurança pública como direito fundamental social, basta olhar a inteligência do artigo $6^{\circ}$ da Constituição Federal:

Art. $6^{\circ}$ São direitos sociais a educação, a saúde, a alimentação, o trabalho, a moradia, o transporte, o lazer, a segurança, a previdência social, a proteção à maternidade e à infância, a assistência aos desamparados, na forma desta Constituição.

Embora o constituinte tenha utilizado da expressão "a segurança", entende-se que o mesmo se refere à segurança pública, juntamente com outros dispositivos constitucionais (SANTIN, 2013, p. 48).

Percebe-se que a segurança pública pensada como direito fundamental social revestese mais claramente de uma concepção de coletividade, de preponderância de interesse difuso (SANTIN, 2005, p. 212; SANTIN, 2013, p. 77-149).

De forma semelhante, Fabretti (2014, p. 115) aponta um aspecto mais coletivo do que individual, escrevendo o seguinte:

No que se refere exatamente ao direito à segurança pública, parece ser impossível individualizá-lo. Ainda que se reconheça a segurança pública como um direito fundamental, ainda que se possa dizer que há um "direito à segurança", parece que seu aspecto é muito mais coletivo que individual.

Por sua vez, Noberto Bobbio (2003, p. 58) ensina que a essência social do indivíduo é emanada do seu próprio "instinto de conservação", ou seja, é por essa necessidade aflorada de autopreservação que surge o Estado, pois devido este ente ser o único detentor de poderes capaz de abarcar todo o grupo social e assim atenuar os choques sociais e conservar a sociedade dos limites da ordem e da paz.

Por todo o exposto fica evidenciado que a segurança pública é inegavelmente um direito fundamental social conforme o texto constitucional e a hermenêutica de sua interpretação. Mais difícil do que classificar como tal, é a efetivação concreta de tal direito tão caro a uma sociedade desigual e injusta como a brasileira; daí a importância no constante aprimoramento das políticas públicas para a busca de manter os projetos que dão resultados positivos e alterar os projetos com resultados não satisfatórios. A busca por serviços públicos com melhor qualidade passa pela adequação destes na busca pelas melhorias. 


\title{
3. SEGURANÇA PÚBLICA: DEVER DO ESTADO, DIREITO E RESPONSABILIDADE DE TODOS
}

A Constituição Federal de 1988 deu especial atenção à Segurança Pública, elencando a referida temática em um capítulo próprio, Capítulo III, do texto constitucional, dentro do Título V, denominado: "Da Defesa do Estado e das Instituições Democráticas”.

Dentro do Título V, além do capítulo III, que trata da Segurança Pública, se tem o Capítulo I, o qual dispõe sobre o Estado de Defesa e o Estado de Sítio; e o Capítulo II, o qual dispõe sobre as Forças Armadas. Neste contexto, Nucci (2016, p. 40) observa:

\begin{abstract}
A segurança pública é justamente a sensação de bem-estar de uma comunidade, certos os seus moradores de que terão uma vida tranquila e pacífica. Livre de aborrecimentos trazidos justamente pela convivência com outras pessoas, por isso, pública. Não há dúvida de que, no art. 144 da Constituição Federal, abrindo o Capítulo III do Título V (Da Defesa do Estado e das Instituições Democráticas), tem-se o tema Da segurança pública, querendo referir-se aos órgãos encarregados de assegurar à sociedade essa paz e bem-estar, que todos merecem no Estado Democrático de Direito. Pode-se sustentar que grande parte do enfoque da segurança pública destina-se a prevenir a ocorrência das infrações penais, mas, ainda insistindo, não é somente isso.
\end{abstract}

De maneira mais detalhada, Santin (2005, p. 211) expõe:

\begin{abstract}
O ser humano tem interesse de viver em ambiente social ordeiro e que a sua vida, saúde e patrimônio sejam respeitados pelos semelhantes e pelo Estado. Entretanto, há uma predominância do interesse difuso de que estes valores sejam preservados em relação ao indivíduo, ao grupo e todas as pessoas em geral, para a manutenção do equilíbrio da sociedade e da ordem pública, que podem ser alteradas e provocar um retorno ao sistema de autotutela, sob o império da lei do mais forte, em substituição à disciplina e solução dos conflitos por meio do Direito e das instituições públicas. Acrescente-se que há valores que são individuais indisponíveis como os direitos à vida, à saúde física e mental, à educação, à liberdade, mas também são considerados direitos difusos.
\end{abstract}

É importante perceber que a segurança pública é um dos principais serviços públicos prestados pelo Estado, mas também possui componentes de participação social de todos os indivíduos. De modo que há uma busca permanente da população pela garantia e continuidade da prestação estatal aqui mencionada, mas esta não deve ser vista apenas como uma retribuição estatal, mas também como uma construção coletiva de toda a sociedade brasileira.

Quanto à natureza jurídica, Santin (2005, p. 212) destaca a segurança pública como interesse difuso: 
Na direção destes argumentos sociais, jurídicos e reais, parece-me que o direito à segurança pública tem característica predominante de direito ou interesse difuso, por ser de natureza transindividual, indivisível, de titularidade dispersa entre pessoas indeterminadas e ligadas por circunstâncias de fato no interesse geral de recebimento de proteção fornecida pelo Estado na preservação da ordem pública e da incolumidade das pessoas e do patrimônio.

O direito à segurança não é individualmente endereçado, mas voltado para toda a coletividade, garantido não somente aos cidadãos brasileiros, mas a todos os seres humanos que estão em território brasileiro. Eis a abrangência do mesmo, o qual deve ser prestado a todo ser humano sem qualquer outra condição. Direitos Humanos e Segurança Pública possuem uma relação de proximidade, e ambos devem caminhar juntos para a construção de uma sociedade mais justa, democrática e menos desigual.

O que se percebe no Brasil é justamente um resquício da ditadura militar, onde a polícia estava afastada da ideia dos direitos humanos. Eis o contexto do que Carneiro e Santin (2020, p. 97), escrevem:

\footnotetext{
Durante muito tempo os segmentos voltados a defesa dos Direitos Humanos se mantiveram afastados das discussões sobre as políticas públicas de segurança no Brasil. No processo de redemocratização, por diversos motivos, os movimentos sociais e demais entidades apresentaram dificuldade no tratamento do tema.
}

Evidentemente romper com ideias enraizadas na sociedade por décadas não é tarefa fácil, mas é urgente que os conceitos da polícia comunitária sejam um norte para os operadores da segurança pública, de modo a vencer os atavismos sociais existentes e buscando o estabelecimento da segurança com cidadania, de modo a compatibilizar plenamente os direitos humanos com a segurança pública.

Há uma presunção de que o tempo para a mudança será longo até que os avanços da atuação policial estejam de acordo com os direitos humanos, mas este é o caminho para a sociedade brasileira atual dentro do estado de direito democrático (CARNEIRO; SANTIN, 2020, p. 99).

Superada a questão dos direitos humanos e sua relação com a segurança pública, percebe-se que a mera possibilidade de descontinuidade da prestação do serviço público da segurança já gera no imaginário coletivo a instalação do caos. Pois uma vez que não haja mais a segurança pública estatal a barbárie e a lei dos mais fortes seriam impostas, como ocorreu na greve dos policiais militares do Espírito Santo. 
Pode-se perceber que o simples conviver com essa constante sensação de insegurança é algo extremamente prejudicial para o convívio social; além de prejudicar o desenvolvimento econômico, as relações comunitárias e o bem-estar de todo uma população que almeja um ambiente de paz social para realizar as atividades humanas com liberdade e garantias do exercício de seus direitos fundamentais.

O constituinte ao abordar a segurança pública reconheceu a importância de que toda a sociedade brasileira seja participante da construção da mesma. Desta forma no caput do artigo 144 da Constituição Federal estabeleceu que:

A segurança pública, dever do Estado, direito e responsabilidade de todos, é exercida para a preservação da ordem pública e da incolumidade das pessoas e do patrimônio (...)

Ao positivar a possibilidade da participação popular na segurança pública, o constituinte retirou a atuação exclusiva do Estado; de modo a dividir o encargo com a sociedade visando atender as necessidades primárias a que se destina o serviço público essencial citado.

Da leitura do texto constitucional é possível perceber que além do dever estatal de proporcionar a segurança pública e do correspondente direito de toda a sociedade brasileira, se estabeleceu como "responsabilidade de todos" a segurança pública. Isso demonstra que a integração e a participação das pessoas que não são operadores da segurança pública são um norte desejável a partir da Constituição Cidadã.

No entanto, cabe ressaltar que esta constitucionalização da responsabilidade de todos, por si só, não tem o escopo de integrar o cidadão nas atividades de segurança pública propriamente dita; mas sim podendo atuar como fiscal dos agentes e dos órgãos integrantes do sistema de segurança pública.

Por isso é importante que os canais de comunicação e interação entre a comunidade e os serviços públicos de segurança pública sejam expandidos. De modo que, a tecnologia esteja a serviço da população como um todo.

Os serviços telefônicos e de transmissão de dados devem propiciar canais de acesso ao fornecimento de informações para as autoridades, de modo que o serviço popularmente conhecido como "disque-denúncia", seja um canal permanente de levantamento de informações das polícias e dos crimes denunciados. E este serviço deve ser disponibilizado na forma do anonimato para que o cidadão denunciante sinta-se mais seguro de realizar a 
denúncia, sem sua exposição futura em relação ao caso específico. Santin fornece outras situações para participação popular na segurança pública (2013, p. 11-124).

Da mesma forma, os programas de aproximação da sociedade com os cidadãos e com o público escolar devem ser ampliados, estimulando a segurança pública com cidadania. Neste sentido, sobre a participação popular, Foureaux (2019, p. 22) estabelece:

Há várias formas da participação popular na segurança pública, como o DisqueDenúncia, cuja identidade do denunciante é mantida no anonimato; projetos de polícia comunitária, como a rede de vizinhos protegidos; reuniões comunitárias; Programa Educacional de Resistência às Drogas e à Violência - PROERD; Programa Jovens Construindo a Cidadania - JCC, dentre outros.

Assim sendo, a participação do cidadão, que não é operador da segurança pública, evidentemente será diversa dos mencionados; pois o cidadão não possui a formação policial, nem as técnicas necessárias para o enfrentamento da criminalidade, a qual constantemente se aperfeiçoa. Da mesma forma, percebe-se que o cidadão além de não possuir treinamento policial para agir diante de um criminoso, também não possui equipamentos e materiais para este enfrentamento.

De modo que a participação da sociedade pode ser mais efetiva no planejamento e na elaboração de políticas públicas ligadas ao policiamento comunitário, onde através do diagnóstico local se possibilite atacar as principais causas da criminalidade. Aproximando assim os representantes da comunidade local junto dos operadores da segurança pública para traçar objetivos realmente realizáveis, e não apenas utopias.

Partindo desta construção, parece que a palavra "todos", mencionada no artigo 144 da Constituição Federal, dentro de uma interpretação constitucional, indica o desejo do constituinte de que a participação popular na gestão da segurança pública se efetive, de forma integrada, entre a sociedade civil e os operadores da segurança pública.

Espera-se assim, uma atitude diferente de toda a população brasileira, deixando de lado a mera passividade em relação à temática da segurança pública, e buscando a construção coletiva e permanente de um ambiente de paz social.

\section{SEGURANÇA PÚBLICA: SERVIÇO PÚBLICO FUNDAMENTAL}

Em uma perspectiva inicial Santin (2019, p. 147) reconhece que o serviço público é ao mesmo tempo direito humano e direito fundamental, ensinando que: 
A colocação do serviço público como direito humano ou direito fundamental é um mecanismo de ação afirmativa, de prestígio e destaque dessa atividade ou função pública, um fator importante para a melhoria da prestação de serviço público ao povo, com inegável capacidade de transformação social, redução das desigualdades, melhor atendimento pelos órgãos públicos e instrumento importante para a efetivação dos direitos sociais e do mínimo existencial.

Assim sendo, inegável é a perspectiva da segurança pública enquanto direito humano e direito fundamental social. Porém a operacionalização de tal direito se dá através do serviço público, no caso o serviço público de segurança pública, o qual é prestado por diversos entes estatais.

No âmbito da União a segurança pública pelas seguintes polícias: polícia federal, polícia rodoviária federal e polícia ferroviária federal. Por sua vez, no âmbito estadual a segurança pública é prestada pelas seguintes instituições: polícia militar e corpo de bombeiros, polícia civil e polícia científica. Por fim, no âmbito municipal há cada vez mais a atuação das guardas municipais em reforço ao combate à criminalidade, numa forte tendência de que estas sejam reconhecidas e transformadas futuramente em polícias municipais, um caminho bem provável.

Para adentrar propriamente na questão dos serviços públicos primeiramente é preciso buscar a conceituação dos mesmos, a qual nas palavras de Santin (2013, p. 25) se tem que:

Serviços públicos são as atividades desenvolvidas pela Administração Pública em prol da coletividade e do cidadão no desempenho de funções estatais, no cumprimento das finalidades públicas, em contraprestação pela arrecadação de tributos pagos pelo povo.

Assim sendo, pode-se afirmar que a prestação dos serviços públicos possui um custo tributário pago por toda sociedade. E daí uma das razões pelas quais se legitima a sociedade cobrar por serviços públicos adequados, com a qualidade e a eficiência desejada.

A segurança pública, assim como os serviços de saúde e de educação, por serem os braços mais visíveis do Estado enquanto retribuição aos tributos arrecadados sempre possuem margem para melhorias. De modo que, por mais excelente que um serviço público possa estar sendo prestado pelo Estado, sempre haverá possibilidades de melhorias na eficiência do mesmo, aliado ao desafio de não perder o nível de qualidade já alcançado nos indicadores de mensuração que devem ser adotados na administração pública moderna. 
Adentrando propriamente no serviço público da segurança pública prestado no Brasil parece que o mesmo enfrenta o desafio da melhoria contínua; seja pelo aumento populacional e da criminalidade, seja pela consciência social desenvolvida pela sociedade brasileira referente ao direito à segurança.

Percebe-se que a violência é um problema que tende a se expandir, principalmente no ambiente em que a Segurança Pública esteja com problemas estruturais, os quais contribuem para o estabelecimento de uma crise na prestação deste importante serviço público para toda sociedade (DEGRAF, 2018, p. 257).

A insuficiência do serviço de segurança pública é percebida rapidamente na vida das pessoas, tornando-se um incômodo, que causa mudanças de rotinas e preocupações decorrentes.

Evidentemente, quanto mais precária a situação socioeconômica do indivíduo mais nítido e sentido é a ausência da segurança pública na vida deste cidadão; uma vez que a segurança privada e as estruturas prediais cercadas por ofendículos são inacessíveis às classes sociais menos abastadas. Assim sendo, percebe-se empiricamente no simples caminhar nas ruas das cidades grandes e de médio porte o enorme crescimento da segurança privada, nas últimas décadas no Brasil. E isto não ocorre por acaso.

É nítido nos processos sociais que: onde há ausência do Estado, outro ator social tende a ocupar o vácuo deixado pela ausência estatal. Em relação à segurança pública não seria diferente. De modo que, aqueles que podem pagar pelos serviços da segurança privada o fazem.

Entre a incerteza de esperar a resposta estatal adequada e a certeza da prevenção privada, esta última se revela um mecanismo razoável para quem pode pagar por tal prestação particular; ainda que não seja esta a solução mais adequada para os problemas da segurança pública, os quais devem ser corrigidos.

Assim percebe-se que a prestação de serviços de segurança privada, vigilância e monitoramento patrimonial cresceram de forma substancial no Brasil. Ainda que isto ocorra de forma complementar e auxiliar, já que as atividades da segurança pública são atividades típicas de Estado, indelegáveis, portanto, fica evidente que há uma sensação de insegurança pública na população. Constata-se que quem pode pagar por este serviço privado o faz, na provável esperança de suprir a ineficiência estatal ou pelo menos mitigar os efeitos da violência no seu cotidiano. 
Em decorrência da ausência da segurança pública em determinados locais, se tem muitas vezes o sentimento coletivo da sensação de insegurança. Isto é algo que perturba as pessoas, uma vez que a insegurança pública gera inúmeros problemas relacionados ao medo da violência e o distanciamento do acesso de outros direitos estabelecidos.

Santin, Manfré e Nascimento (2018, p. 199) neste sentido esclarecem:

Assim, torna-se necessária e urgente a implementação de políticas públicas no campo da segurança, não somente como resposta ao clamor social momentâneo, mas como atividade concreta para a prevenção e repressão ao crime e como instrumento legítimo de emancipação social, que se relaciona à promoção de uma vida com dignidade.

De modo que, é necessário que a população brasileira compreenda que ao lado da saúde pública universal com qualidade e da educação pública universal com qualidade também se deve buscar a construção de políticas públicas que realmente busquem a efetivação de uma segurança pública universal e com qualidade.

Este tripé constituído de saúde, educação e segurança deveriam ser o principal norte para todos os governantes; pois tais direitos são o mínimo essencial para a construção de um Estado que traga as mínimas condições de dignidade para sua população.

Buscar permanentemente melhorias na saúde, na educação e na segurança são atitudes que vão além de qualquer programa de governo; e constituem antes de qualquer outra finalidade a realização dos legítimos propósitos que justificam a própria existência do Estado.

Neste sentido, Santin (2013, p. 17) ensina:

O Estado é uma figura artificial, que tem o monopólio da força e usa o poder da soberania e da violência simbólica para a imposição e arrecadação de tributos, como meio para a obtenção de recursos para atendimento de suas finalidades de bem-estar social. O poder público beneficia a sociedade e o cidadão pela prestação de serviços públicos.

Da percepção inicial, e das inúmeras notícias no Brasil, onde constantemente o mesmo aparece elencado na lista dos países com as maiores cargas tributárias do mundo fica a incompreensão da ineficiência dos serviços públicos disponíveis, entre eles o serviço da segurança pública, uma vez que os recursos financeiros existem e são arrecadados através da voracidade fiscal brasileira. 
A adequação dos serviços públicos de segurança pública é uma construção de gestão efetiva no melhor emprego dos recursos públicos destinados a esta prestação estatal fundamental.

De modo que é preciso aperfeiçoar a aplicação dos recursos públicos existentes de forma inteligente, dentro de um planejamento focado em metas e resultados. Assim sendo, as políticas públicas de segurança pública poderão avançar de encontro aos desejos da sociedade brasileira.

Mensurar os resultados, erros e acertos, criar métricas para a análise da segurança pública são ferramentas necessárias para a melhoria da prestação deste serviço público, tornando-o mais eficiente.

\section{CONSIDERAÇÕES FINAIS}

Inegável a importância da Segurança Pública, no mundo todo, é o que dá estabilidade interna aos governos, e dá possibilidades da continuidade de um projeto de Estado, na construção de uma nação com paz social.

A sensação de segurança é algo de interesse coletivo, e isto só será possível quando ocorrer à efetivação do direito fundamental social da segurança. E nisto é importante perceber que é um trabalho permanente, pois a ausência de políticas públicas de segurança pode abrir espaço para retrocessos neste campo.

Diminuir as desigualdades sociais, tão visíveis no Brasil, passa necessariamente pela ampliação da qualidade e adequação da segurança pública existente no país, para que todas as classes sociais tenham a percepção da segurança em suas vidas e de que o trabalho policial está efetivamente sendo realizado.

Após a exposição de alguns pontos doutrinários existentes percebe-se a importância da segurança pública enquanto direito fundamental social, e da necessidade permanente da construção de uma segurança pública com cidadania e participação de toda a sociedade brasileira neste processo, reafirmando o desejo do constituinte na Carta Magna vigente, em característica predominante de interesse difuso.

Conscientizar a população brasileira da importância de se construir uma política pública que busque a efetivação de uma segurança pública universal com qualidade parece ser o primeiro passo para que realmente a responsabilidade de todos, expressa no artigo 144 da 
Constituição Federal de 1988, não seja apenas mero texto constitucional, mas um ideal realizável no Brasil.

Mais do que nunca, a segurança pública precisa assumir os contornos e a importância que a Carta Magna estabeleceu através do constituinte de 1988. Pois assim, a mesma estará contribuindo para a construção de um país desenvolvido e uma nação com um povo próspero e que viva numa sociedade de efetiva paz social, aonde os sonhos individuais irão muito além da incerteza de ser a próxima vítima da criminalidade.

Estimular a população e as autoridades na fiscalização e no controle da boa aplicação dos recursos públicos no serviço público da segurança pública são medidas de urgência numa sociedade que tem a segurança pública não somente como dever estatal, mas também como direito e responsabilidade de todos.

Mais do que nunca é preciso implantar métricas de aferição da qualidade dos serviços de segurança pública prestados pelas inúmeras instituições policiais existentes; pois somente com o diagnóstico das falhas será possível implantar as correções e as adequações deste importante direito fundamental social prestado na forma de serviço público.

Quando os erros forem detectados, os acertos corretivos serão possíveis. Somente com a análise e a adequação, a tão esperada excelência e qualidade da segurança pública poderão ser buscadas.

\section{REFERÊNCIAS}

BOBBIO, Norberto. Estado, governo, sociedade: para uma teoria da política. Rio de Janeiro: Paz e Terra, 2003.

BONAVIDES, Paulo. Curso de Direito Constitucional. 28. ed. São Paulo: Malheiros, 2013.

BRASIL. Constituição da República Federativa do Brasil de 1988, promulgada em 5 de outubro de 1988. Disponível em:

http://www.planalto.gov.br/ccivil_03/Constituicao/Constituicao.htm. Acesso em: 20 jun. 2020.

BRASIL. Decreto n. 592, de 6 de julho de 1992. Atos Internacionais. Pacto Internacional sobre Direitos Civis e Políticos. Disponível em: http://www.planalto.gov.br/ccivil_03/decreto/1990-1994/d0592.htm. Acesso em: 20 jun. 2020 .

BRASIL. Emenda Constitucional n. 45, de 30 de dezembro de 2004. Altera dispositivos dos arts. $5^{\circ}, 36,52,92,93,95,98,99,102,103,104,105,107,109,111,112,114,115,125,126$, 127, 128, 129, 134 e 168 da Constituição Federal, e acrescenta os arts. 103-A, 103B, 111-A e 130-A, e dá outras providências. Disponível em: 
http://www.planalto.gov.br/ccivil_03/constituicao/emendas/emc/emc45.htm. Acesso em: 20 jun. 2020.

BULOS, Uadi Lamnêgo. Curso de direito constitucional. 8. ed. São Paulo: Saraiva, 2014.

CARNEIRO, Robyson Danilo; SANTIN, Valter Foleto. Direitos Humanos no âmbito das Polícias Militares: enfrentando o antagonismo através da educação. In: I ENCONTRO VIRTUAL DO CONPEDI. 2020, Florianópolis. HOGEMANN, Edna Raquel Rodrigues Santos; OLIVEIRA, Armando Albuquerque de (Coord.). Anais... Florianópolis: CONPEDI, 2020, p. 91-110. Disponível em:

http://conpedi.danilolr.info/publicacoes/olpbq8u9/ro22fnsg/Pm3kbd27sd9iSLk8.pdf. Acesso em: 22 set. 2020.

COSTA, Ilton Garcia; VEIGA, Fábio da Silva; NOGAS, Matheus. Ubiquidade Constitucional e Direitos Fundamentais. Revista Relações Internacionais do Mundo Atual. Curitiba, v. 4, n. 25, p. 97-114, out./dez. 2019. Disponível em:

http://revista.unicuritiba.edu.br/index.php/RIMA/article/view/4022/371372341. Acesso em: 10 set. 2020.

COSTA, Ilton Garcia; PUGLIESI, Renan Cauê Miranda; CACHICHI, Rogério Cangussu Dantas. Superando Paradigmas: A Aplicação da Justiça Restaurativa em Casos que envolvem Violência Doméstica. Revista Brasileira de Ciências Criminais, v. 137, 2017, p. 121-141.

DEGRAF, Guilherme. O fracasso do Estatuto do Desarmamento: considerações sobre a restauração do direito à autodefesa. In: MARGRAF, Alencar Frederico; COSTA, Cleverson Paulo Sant'Ana; MARGRAF, Priscila de Oliveira (Org.). Direitos fundamentais: uma abordagem interdisciplinar. Florianópolis: EMais Editora e Livraria Jurídica, 2018, p. 249266.

FABRETTI, Humberto Barrionuevo. Segurança pública: fundamentos jurídicos para uma abordagem constitucional. São Paulo: Atlas, 2014.

FOUREAUX, Rodrigo. Segurança pública. Salvador: JusPodivm, 2019.

HERRERA, Carlos Miguel. Estado, constituição e direitos sociais. Revista da Faculdade de Direito da Universidade de São Paulo, São Paulo, v. 102, p. 371-395, jan./dez. 2007.

KANT, Immanuel. Resposta à pergunta: “O que é o iluminismo?”. Tradução Artur Mourão. 2008. Disponível em: http://www.lusosofia.net/textos/kant_o_iluminismo_1784. Acesso em: 01 jul. 2020.

KANT, Immanuel. A Paz Perpétua: um projecto filosófico. Tradução Artur Mourão. 2008. Disponível em: http://www.lusosofia.net/textos/kant_immanuel_paz_perpetua.pdf. Acesso em: 01 jul. 2020.

LORENZETTI. Ricardo Luís. Teoria da Decisão Judicial: fundamentos de direito. Tradução Bruno Miragem e Claudia Lima Marques. São Paulo: Revista dos Tribunais, 2009. 
NUCCI, Guilherme de Souza. Direitos humanos versus segurança pública. Rio de Janeiro: Forense, 2016.

ORGANIZAÇÃO DAS NAÇÕES UNIDAS. Declaração Universal dos Direitos Humanos. 1948. Disponível em: https://nacoesunidas.org/wp-content/uploads/2018/10/DUDH.pdf.

Acesso em: 20 jun. 2020.

PAULO, Vicente; ALEXANDRINO, Marcelo. Direito Constitucional descomplicado. 9. ed. São Paulo: Método, 2012.

SANTIN, Valter Foleto. Controle Judicial da Segurança Pública: eficiência do serviço na prevenção e repressão ao crime. 2. ed. São Paulo: Verbatim, 2013.

SANTIN, Valter Foleto. O Ministério Público na investigação criminal. 2. ed. rev. e ampl. Bauru: Edipro, 2007.

SANTIN, Valter Foleto. Característica de direito ou interesse difuso da segurança pública. Argumenta Journal Law, Jacarezinho, n. 5, p. 208-216, 2005. Disponível em: http://seer.uenp.edu.br/index.php/argumenta/article/view/48/49. Acesso em: 23 set. 2020.

SANTIN, Valter Foleto; MANFRÉ, Gabriele Delsasso Lavorato; NASCIMENTO, Francis Pignatti do. Segurança pública, serviço público essencial e planejamento para a busca da paz. Revista Paradigma, v. 27, n. 3, p. 185-206, 14 dez 2018. Disponível em: http://revistas.unaerp.br/paradigma/article/view/1190. Acesso em: 25 set. 2020.

SANTIN, Valter Foleto. Serviço Público e Direitos Humanos. Revista Paradigma, v. 28, n. 2, p. 134-153, 20 nov. 2019. Disponível em:

http://revistas.unaerp.br/paradigma/article/view/1332. Acesso em: 26 set. 2020.

TEIXEIRA, Marcio Aleandro Correia. A polícia no Maranhão: transitando entre poder, violência e luta por direitos. In: XXVI Congresso Nacional do CONPEDI. 2017, Florianópolis. Anais... Florianópolis: CONPEDI, 2017, p. 6-26. Disponível em: http://conpedi.danilolr.info/publicacoes/27ixgmd9/7hf15gnq/BnhSXcNWq0VodsOF.pdf. Acesso em: 10 jul. 2020. 